\title{
A study of incremental sheet forming by using water jet
}

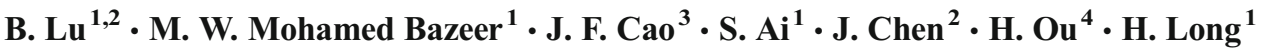

Received: 30 May 2016 / Accepted: 2 November 2016 / Published online: 3 January 2017

(C) The Author(s) 2016. This article is published with open access at Springerlink.com

\begin{abstract}
In this work, a variant of the incremental sheet forming (ISF) process, namely the incremental sheet forming by using water jet (ISF-WJ), was studied. In the investigation, an ISF-WJ prototype machine was designed and developed. Different design concepts of the water jet nozzle were proposed and evaluated to achieve the maximum forming pressure by performing computational fluid dynamic (CFD) simulations. Based on the forming pressure distribution modeled by CFD simulations, finite element (FE) models were developed to study the sheet deformation behavior under the ISFWJ process condition. Based on the understanding gained from the numerical study, experiments were conducted to validate the ISF-WJ process and the developed prototype machine. The results suggest that ISF-WJ is a feasible process to achieve improved surface finish of thin sheet parts. In addition, this study has found that water jet pressure plays an important role in preventing sheet wrinkling and obtaining an accurate geometry of formed parts.
\end{abstract}

Keywords Incremental sheet forming · Water jet · Material plastic deformation

H. Long

h.long@sheffield.ac.uk

1 Department of Mechanical Engineering, The University of Sheffield, Sheffield, UK

2 Department of Plasticity Technology, Shanghai Jiao Tong University, Shanghai, China

3 School of Hydraulic Energy and Power Engineering, Yangzhou University, Yangzhou, China

4 Department of Mechanical, Materials and Manufacturing Engineering, The University of Nottingham, Nottingham, UK

\section{Introduction}

Incremental sheet forming (ISF) has attracted increasing research attentions due to its ability to produce prototypes and small-batch sheet metal parts with complex geometrical features. In the ISF process, one or two ball-nose tools are employed to form a sheet blank incrementally via specific toolpaths according to the desired geometry of a sheet part [1]. Compared to conventional sheet metal forming processes, such as stamping, the ISF does not require specified dies and thus reduces tool costs and improves process flexibility. During the ISF process, localized deformation of the sheet occurs around the area where the tool is in contact with the sheet blank, thus reducing the forming load. Due to the nature of incremental deformation, the ISF process has obvious advantages over conventional forming processes, including improved formability, reduced forming load, and lower costs of tooling and forming equipment. Detailed reviews of technological development of ISF processes have been published in the papers by Jeswiet et al. and Emmens et al. [2, 3].

In recent development, a number of variations of the ISF processes were proposed, such as the conventional singlepoint incremental forming (SPIF) [4], the two-point incremental forming (TPIF) [5], the hybrid incremental forming [6], and the double-side incremental forming (DSIF) [7]. In all these processes, a rigid tool has to be employed to deform the sheet blank. The hard contact between the tool and sheet can inevitably cause poor surface finish. As a result, some alternative tool designs, such as roller-ball tool, were developed [8]. To overcome the surface finishing problem, another variant ISF method was proposed by Ieski $[9,10]$. Using this method, a high-pressure water jet was employed, replacing the conventional rigid tool, to deform the sheet blank. Compared to the conventional ISF method, the incremental sheet forming by using water jet (ISF-WJ) approach induces less friction at 
the interface between water and sheet, no tool wear, or corresponding contamination from the lubricant. These benefits are attractive especially for forming products associated for medical applications. Iseki $[9,10]$ tested the concept of ISF-WJ to produce sheet parts of various geometries, such as cone, pyramid, and embossed plates. To increase the forming force required to plastically deform the sheet blank, Iseki and $\mathrm{T}$. Nara [11] proposed an ISF method combining water jet with shots so that stainless steel sheets with $0.3-\mathrm{mm}$ thickness were formed successfully. Emmens [12] used a set of rotating, columned water jets to expand and reshape the beverage cans. His work clearly showed the benefits of using high-speed water jet in forming, i.e., the high production efficiency for sheet metal parts with complex shapes, in comparison with the conventional ISF process. Jurisevic et al. [13] also investigated the ISF-WJ process by adapting a water jet cutting machine, using reduced water jet pressure and increased flow rate. By comparing the ISF and ISF-WJ, they suggested that the ISF-WJ was compared favorably to the conventional ISF in process flexibility, surface integrity, tooling and equipment costs, and environmental impact, except one unfavorable aspect in terms of forming accuracy. To increase the forming accuracy, Jurisevic et al. [14] introduced a laminated tool to support the sheet in the ISF-WJ process, which resulted in forming time reduction and part quality improvement. Aiming to derive the technological window of water jet sheet forming process, Sajn et al. [15] carried out numerical modeling and finite element simulation to obtain pressure and velocity distributions, by considering turbulent fluid flow through nozzle and water jet impact on a flat rigid surface. Numerical results were in good agreement with those obtained experimentally to provide an insight of the influence of water jet pressure and water jet nozzle diameter on the process. In a recent work, Zhang et al. [16] studied high-pressure oil jet incremental forming by simulating the effects of the geometrical parameters of the conical nozzle on the dynamic pressure and velocity distributions. The material deformation of aluminum sheets of $0.3-\mathrm{mm}$ thickness under different oil pressures was modeled, which concluded that the oil pressure of $15 \mathrm{MPa}$ was suitable for the aluminum sheet material tested.

The previous studies demonstrated not only the advantages of ISF-WJ technology but also the complicity of interaction between high-speed fluid and sheet structure and the sheet deformation behavior under different water jet pressure levels. In addition, previous ISF-WJ studies were generally conducted using water jet cutting machines and few dedicated ISF-WJ devices were made for the experimental investigation. Limited studies were reported in developing water jet nozzle designs to achieve the required forming pressure and investigating how the nozzle design affects jet pressure distributions.

In this work, a new ISF-WJ prototype machine was developed to investigate ISF-WJ and ISF processes. Based on computational fluid dynamic (CFD) simulation, a water jet nozzle was designed to obtain the maximum forming pressure from high-speed water jet. To investigate the material deformation under ISF-WJ process condition, finite element (FE) simulation and experiments were conducted and the sheet deformation behavior was evaluated. Conical sheet metal parts with improved surface finish can be successfully obtained by using the developed ISF-WJ prototype machine. The numerical simulation and experimental testing results suggest that the water jet pressure is a key process parameter to prevent sheet wrinkling during processing and to obtain the accurate geometry of formed parts.

\section{ISF-WJ prototype machine development}

To facilitate the ISF-WJ process, an ISF-WJ prototype machine system has been designed and developed as shown in Fig. 1. The system consists of high- and low-pressure pumps, a water jet nozzle, a sheet fixture, a motion drive system, a control system, and a water tank. The low-pressure pump draws water from the recycling water tank to the highpressure pump to increase water pressure to about $10 \mathrm{MPa}$. The high-pressure water jet then flows through a specially designed water jet nozzle. The nozzle is designed with a gradually reduced nozzle diameter to increase the water jet velocity at the nozzle outlet. The high-pressure water jet flows out of the nozzle outlet onto the sheet surface, which generates a distributed high forming pressure. By using high-pressure water jet to replace the rigid tool, the sheet metal can be deformed gradually by controlling the relative motion between sheet fixture and water jet nozzle using the control system developed. During the deformation process of the sheet, the water coming out of the nozzle remains in the water tank for recycling. In this way, no water will be wasted in the forming process.

The sheet blank is fixed on the sheet fixture which moves with the motion drive system; the sheet is mounted vertically; thus, the sheet surface is perpendicular to the water jet from the nozzle. The water jet nozzle is stationary and fixed onto a

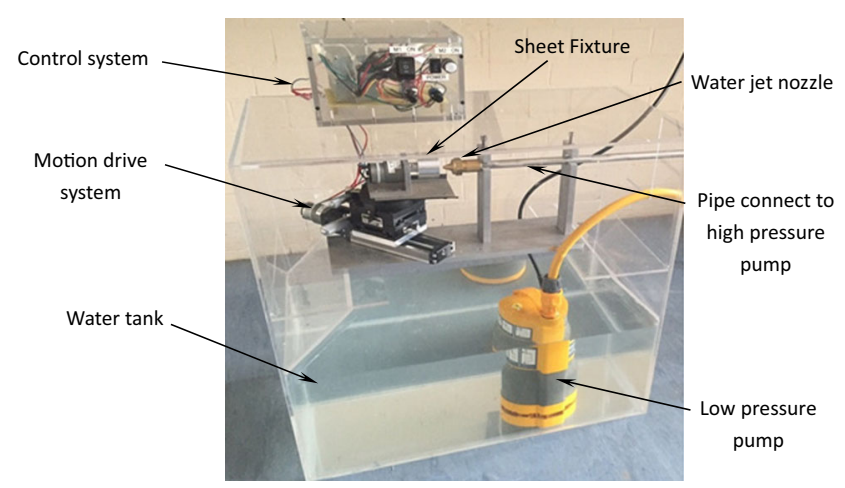

Fig. 1 Developed ISF-WJ prototype machine 
base plate, positioned on the support of the water tank, as shown in Fig. 1. The water jet nozzle is connected to a Karcher HD 5/11 C high-pressure pump with a maximum flow rate of approximately $8.33 \mathrm{~L} / \mathrm{min}$. The water to the high-pressure pump is supplied by a submersible lowpressure pump that is placed inside the water tank.

For this ISF-WJ prototype machine, the developed motion drive system is shown in Fig. 2, where a stand is mounted on its top to support the sheet fixture. A linear motion guide and a rotating base are employed to provide 2-DOF motions of the stand. The linear guide and rotating base are driven by two different DC motors with attached gearboxes. The sheet fixture is mounted on the stand of the motion drive system. Therefore, the fixture could be moved linearly and rotated about its own central axis. The linear guide can be adjusted to be positioned at different angles to the axis of the rotating base, at $30^{\circ}, 45^{\circ}$, and $60^{\circ}$, respectively. The motors are driven by the control system developed; thus, the velocity and direction of motion of the stand can be adjusted as required. As the water jet nozzle is fixed on the base plate, the relative motion between sheet fixture and nozzle can be obtained by moving the sheet fixture. This is different from the conventional ISF where the rigid tool is moved to provide both linear and rotational movements required. Using the motion drive system developed, sheet metal samples with conic shapes of various cone angles can be formed.

\section{ISF-WJ nozzle design}

To test the ISF-WJ process, the water jet nozzle plays an important role in transferring the water jet flow into the required forming pressure. In this work, four water jet nozzle design concepts are proposed as shown in Fig. 3. In all these designs, the external geometry of the nozzles is the same, as shown in Fig. 3e. In all designs, the diameter of the nozzle at the water jet inlet of $8 \mathrm{~mm}$ is decreased to $1.2 \mathrm{~mm}$ at the water jet outlet. As shown in Fig. 3a, b, in designs 1 and 2, the nozzle diameter decreases from 8 to $1.2 \mathrm{~mm}$ linearly and in a quadratic profile, respectively. In designs 3 and 4 shown in

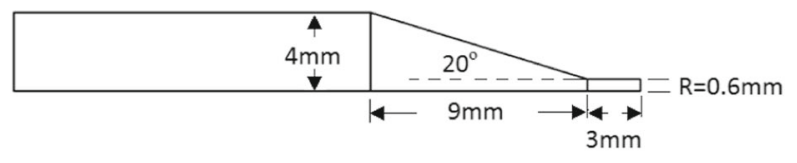

(a) Design 1

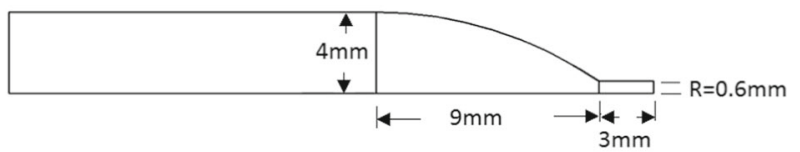

(b) Design 2

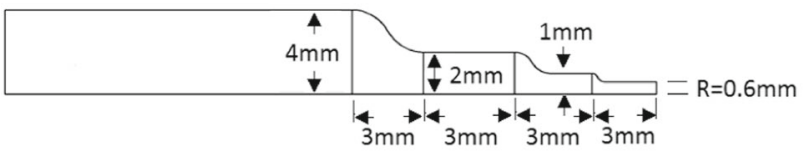

(c) Design 3

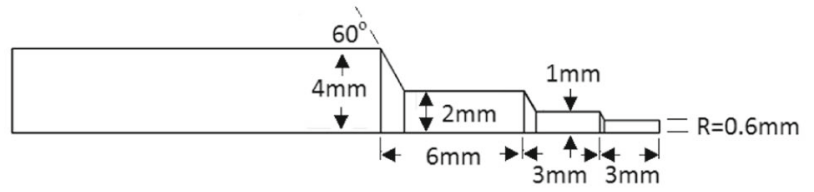

(d) Design 4

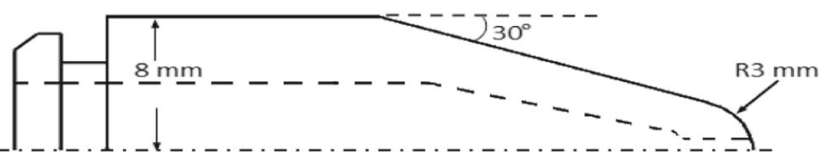

(e) External dimensions of the nozzle

Fig. 3 Four proposed nozzle design concepts. a Design 1. b Design 2. c Design 3. d Design 4. e External dimensions of the nozzle

Fig. 3c, d, the nozzle diameter decreases in three stepped stages with curved or linear fillets, respectively.

Different nozzle designs may result in variations of jet velocity at outlet of the nozzle and thus changes in forming pressure applied on the sheet surface. In this work, using CFD simulations by the ANSYS/Fluent software, the water jet velocity and pressure distributions for these four different nozzle design concepts are evaluated. The viscous turbulence model $k-\omega$ is employed in the analysis, and the SIMPLEC algorithm is used in the simulations. Time step increments for
Fig. 2 Developed motion drive system. a Drive system developed. b CAD model

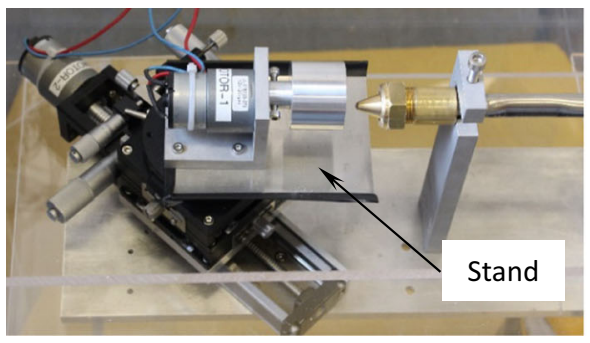

(a) Drive system developed

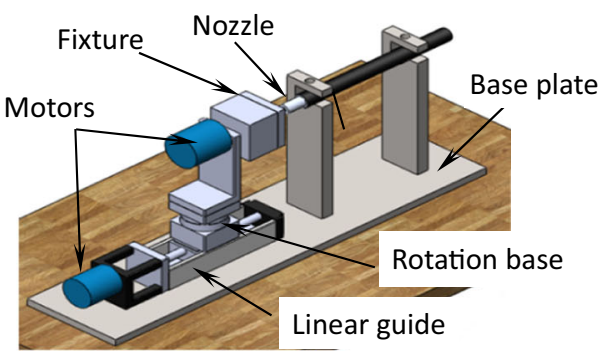

(b) CAD model 
Fig. 4 Comparison of water jet pressure inside the nozzle. a Design 1. b Design 2. c Design 3. d Design 4. e Pressure distributions on the sheet along radius

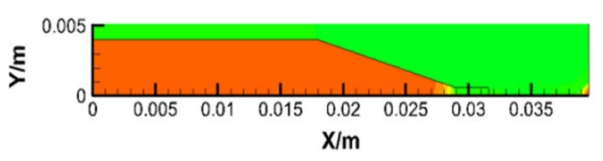

(a)

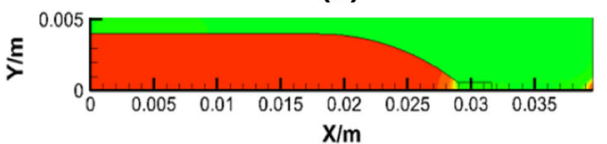

(b)

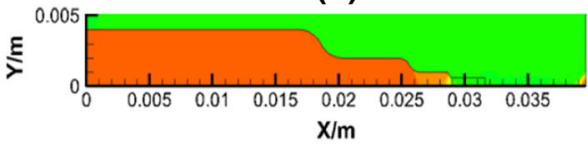

(c)

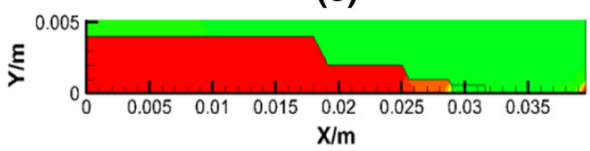

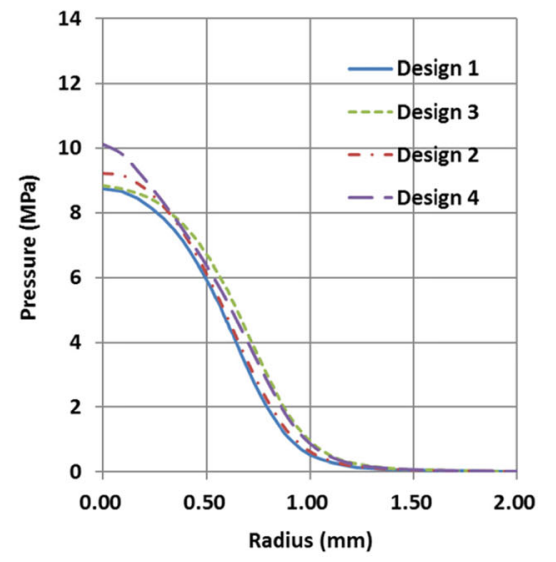

(e)

(d)

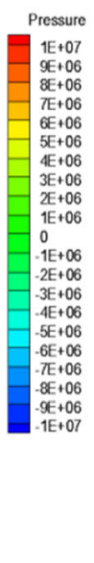

\begin{tabular}{l}
$1 E+07$ \\
$9 E+06$ \\
$9 E+06$ \\
$8 E+06$ \\
$7 E+06$ \\
\hline $6 E+06$ \\
$-5 E+06$ \\
$-4 E+06$ \\
$-3 E+06$ \\
$-2 E+06$ \\
$-1 E+06$ \\
-0 \\
$-1 E+06$ \\
$-2 E+06$ \\
$-3 E+06$ \\
$-4 E+06$ \\
$-5 E+06$ \\
$-6 E+06$ \\
$-7 E+06$ \\
$-8 E+06$ \\
$-9 E+06$ \\
$-1 E+07$ \\
\hline
\end{tabular}

all design concepts are set to be the value of $1 \mathrm{e}-6$. The water flow rate is chosen to be $8.6 \mathrm{~L} / \mathrm{min}$ with an inflow velocity of $2.852 \mathrm{~m} / \mathrm{s}$. The water density is $998.2 \mathrm{~kg} / \mathrm{m}^{3}$, and the air density is $1.025 \mathrm{~kg} / \mathrm{m}^{3}$.

Using CFD simulation, the water jet pressure variations while the water flows through the nozzle channel are modeled by and shown in Fig. 4a-d. The pressure distributions along the radial direction of the forming sheet are illustrated in Fig. 4e. It can be seen that the maximum pressure of $10.5 \mathrm{MPa}$ is achieved by design 4 . The quadratic nozzle channel design in design 2 has a maximum pressure of about $9 \mathrm{MPa}$. However, in designs 1 and 3, the internal water pressure values are lower than those of the other two design concepts. The pressure distributions on the sheet surface are similar for all designs, confined in a small area of less than $3 \mathrm{~mm}$ in diameter on the forming sheet. However, the maximum pressure values are different: design 4 nozzle generates the highest pressure value among the four proposed designs. In this work, design 4 nozzle is manufactured to perform experiments.

To study the effect of initial distance between the nozzle head and the deformed sheet surface, further CFD simulations are performed to evaluate how it affects the maximum pressure value. Figure $5 \mathrm{a}$ shows the maximum pressure values when the initial distances are 1, 5, 8, 15, and $30 \mathrm{~mm}$, respectively. Figure $5 \mathrm{~b}$ compares the pressure distributions when the distance equals to 8 and $15 \mathrm{~mm}$, respectively. It can be seen that the initial distance between the nozzle head and the deformed sheet surface has a considerable effect on the pressure distribution and the maximum pressure values. These CFD pressure results will be useful in determining parameters in the experimental testing and FE simulation, detailed in the following sections.
Fig. 5 Effect of distance between nozzle head and sheet on maximum pressure. a Comparison of maximum forming pressures. b Comparison of pressure distributions (a)

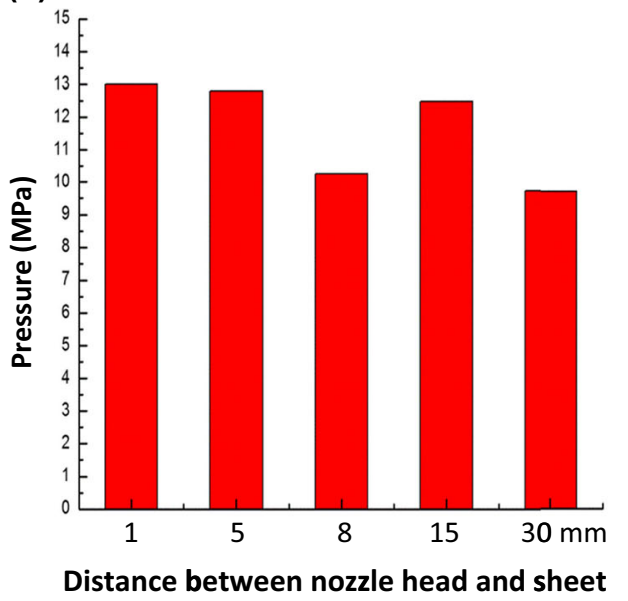

(b)

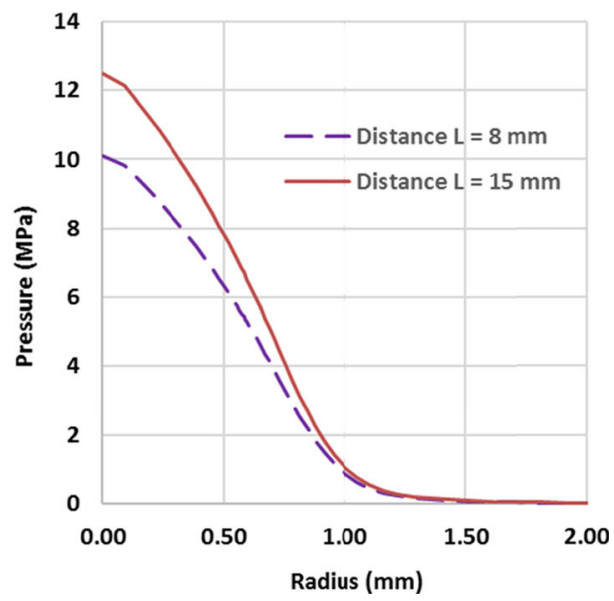


Fig. 6 FE models and toolpaths. a ISF-WJ FE model. b ISF-WJ toolpath. $\mathbf{c}$ ISF FE model. d ISF toolpath

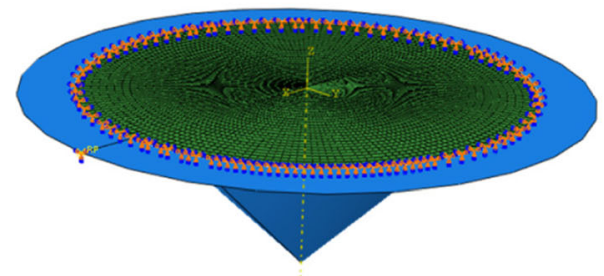

(a)

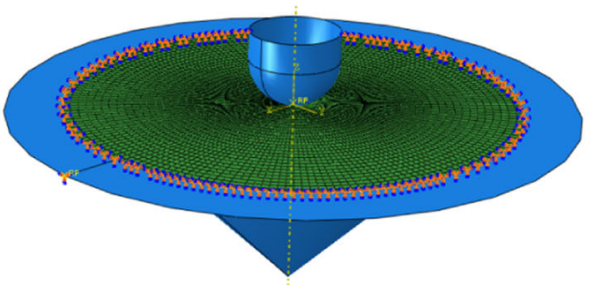

(c)

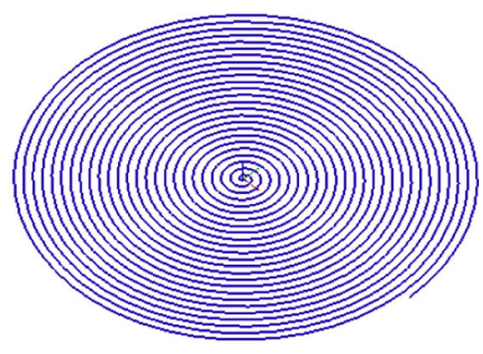

(b)

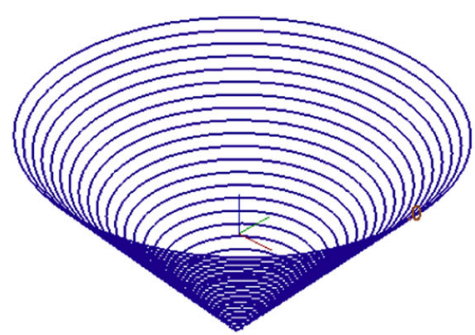

(d)

\section{Finite element simulation and experimental testing}

Using the developed prototype machine and nozzle designs, FE simulations of both ISF-WJ and ISF processes are performed by using the ABAQUS software. The sheet blank is meshed, and the toolpaths for ISF-WJ and ISF are generated, respectively, as shown in Fig. 6. In the FE models, the sheet with a radius of $15 \mathrm{~mm}$ is placed on a conical supporting die with a wall angle of $45^{\circ}$. Shell elements with a maximum size of $0.5 \mathrm{~mm}$ are used to create FE mesh for the sheet, while the supporting die is defined as analytical rigid. For the ISF-WJ process, the forming pressure produced by high-pressure water jet is applied on the deformable sheet by using ABAQUS user subroutine function, VDLoad. In this subroutine, the pressure distribution calculated by CFD simulations, shown in Fig. 4e, is applied on the ISF-WJ sheet, shown in Fig. 6a.

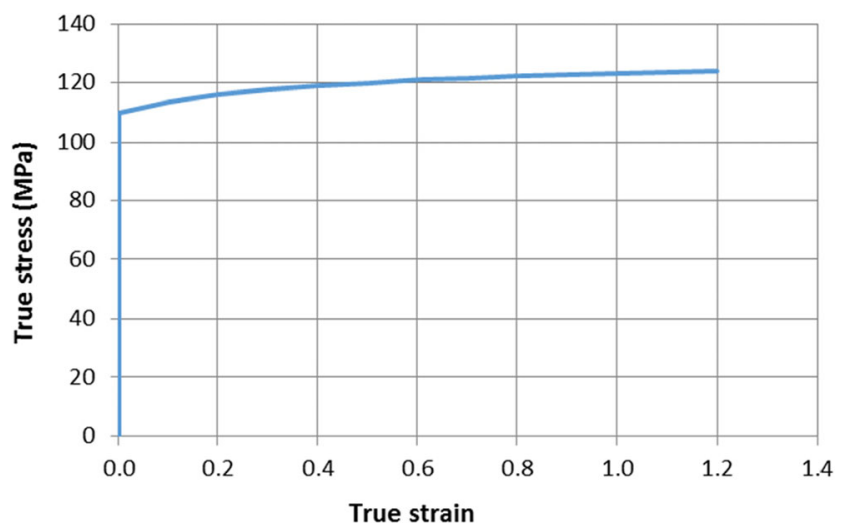

Fig. 7 Flow stress curve of AA1060
The water jet nozzle toolpath, as illustrated in Fig. $6 \mathrm{~b}$, is employed to deform the sheet gradually in the simulation. For the ISF process, a rigid tool with radius of $3 \mathrm{~mm}$ is employed to deform the ISF sheet, as shown in Fig. 6c, and this tool is moved according to the generated ISF toolpath as shown in Fig. 6d. The flow stress of pure aluminum AA1060 used in the FE models is obtained from a material database. Figure 7 shows the flow stress curve as defined in ABAQUS FE models. Both elastic and plastic properties of the material are defined; therefore, both elastic and plastic deformations are modeled in this work.

However, ultra-thin metallic sheets may exhibit different behaviors compared to thick sheets when subject to deformation. Future studies should be carried out to characterize the material elastic and plastic behavior; thus, the FE models developed can accurately capture the deformation behavior of the thin sheets under the ISF-WJ and ISF process conditions.

Using the developed FE models, both ISF-WJ and ISF processes with different process conditions are simulated according to five simulation cases using the process parameters

Table 1 ISF-WJ and ISF FE simulation cases

\begin{tabular}{llll}
\hline Case no. & Process & Sheet thickness (mm) & Max pressure (MPa) \\
\hline 1 & ISF-WJ & 0.17 & 9.5 \\
2 & ISF-WJ & 0.17 & 10.5 \\
3 & ISF-WJ & 0.1 & 10.5 \\
4 & ISF-WJ & 0.17 & 11.5 \\
5 & ISF & 0.17 & - \\
\hline
\end{tabular}


Fig. 8 Incremental forming processes with and without water jet. a ISF-WJ. b ISF without lubricant

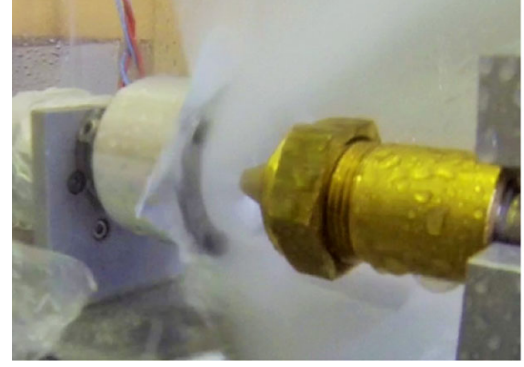

(a) ISF-WJ

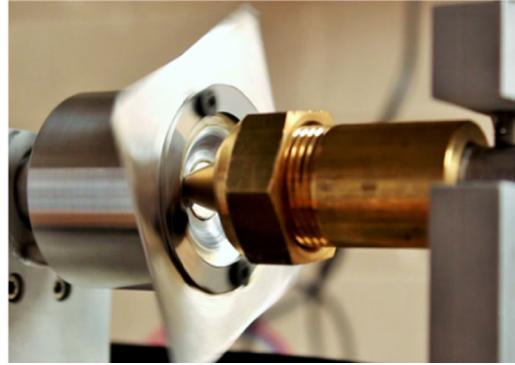

(b) ISF without lubricant given in Table 1. Based on the forming pressure distributions produced by CFD simulations, in the FE simulation, three different maximum forming pressure values, 9.5, 10.5, and 11.5 $\mathrm{MPa}$, are used to study the effect of forming pressure on sheet deformation. In addition, the effect of sheet thickness on deformation is also studied by defining 0.1 and $0.17 \mathrm{~mm}$, respectively, as sheet thickness in the simulation. Due to the limitation of the high-pressure pump, the maximum flow rate of approximately $8.33 \mathrm{~L} / \mathrm{min}$, only a very soft material of AA1060 of thin sheets with thickness of 0.1 and $0.17 \mathrm{~mm}$ is used in the study. However, if more powerful water jet pumps can be employed, harder materials such as aluminum alloys and thin steel sheets may be deformed by using the machine concept developed. The load capacity of the machine for ISF processes will be determined by the motors and gearboxes used. While ISF-WJ may have potential applications for soft materials and thin sheets, it is challenging to process harder to deform materials.

In the experiments, both ISF-WJ and conventional ISF processes are conducted by using the developed system as shown in Fig. 8. In the ISF-WJ process, the sheet can be deformed by using the high forming pressure generated from water jet. In the conventional ISF process, the sheet can be directly formed by employing the nozzle as a rigid tool.

In the experimental testing, both ISF and ISF-WJ processes are tested using the parameters given in Table 2. Because the water jet pressure cannot be further increased beyond using the maximum flow rate of approximately $8.33 \mathrm{~L} / \mathrm{min}$ provided by the pressure pumps employed in the prototype system, thin sheets with thickness of 0.1 and $0.17 \mathrm{~mm}$ are used. The

Table 2 Experimental test cases

\begin{tabular}{lllll}
\hline Case no. & Process & $\begin{array}{l}\text { Sheet thickness } \\
(\mathrm{mm})\end{array}$ & $\begin{array}{l}\text { Max } \\
\text { pressure }(\mathrm{MPa})\end{array}$ & Lubricant \\
\hline 2 & ISF-WJ & 0.17 & 10.5 & No \\
3 & ISF-WJ & 0.1 & 10.5 & No \\
5 & ISF & 0.17 & - & Yes \\
\hline
\end{tabular}

rotational speed of the sheet is $52 \mathrm{rpm}$ and is fed at an angle of $45^{\circ}$ to the nozzle axis. The conventional ISF process (case 5 ) is also performed as a benchmark test for comparison with the ISF-WJ processes (cases 2 and 3). In the ISF processes, tests with and without use of a lubricant are performed, while in the ISF-WJ processes shown in Fig. 8a, no lubricant is used. Figure $8 \mathrm{~b}$ shows the ISF setup without lubrication, while case 5 tests the ISF with lubrication. In general, lubricant is always used in the ISF process to improve sheet surface finish and to reduce tool wear.

\section{Results and discussion}

\subsection{Finite element results of sheet deformation}

The equivalent plastic strain distributions obtained by the FE simulation for cases $1-5$ are shown in Fig. 9. The heights ( $Y$ value) of formed conic shapes for the five simulated cases are shown in Fig. 10. As can be seen in Fig. 9, for cases 2 and 3 with $10.5 \mathrm{MPa}$ as the maximum forming pressure, the conical part can be completely formed with an average equivalent plastic strain of around 0.66. However, at the tip area of the cone, higher strain values can be observed, especially for case 3 . This higher localized strain at tip area implies a higher risk of wrinkling of the formed cone. For case 1 with a lower maximum forming pressure of 9.5 $\mathrm{MPa}$, a lower average plastic strain of about 0.5 can be observed. For the ISF case, at the sidewall of the cone, an average plastic strain of about 0.94 can be observed, much higher than that of the ISF-WJ cases, due to the direct metal-to-metal contact by using the rigid tool. There is a higher plastic deformation zone at the bottom area of the cone; this is because the ISF tool finishes its toolpath in the localized area.

Figure 10 shows the comparison of the height of the formed cone shape in different simulated cases. Case 1 has the smallest height than that of other cases, resulting the formed cone to be further deviated from the designed conic shape. For case 4 with a higher 
Fig. 9 Distributions of equivalent plastic strain by ISFWJ and ISF. a Case 1. b Case 2. c Case 3. d Case 4. e Case 5

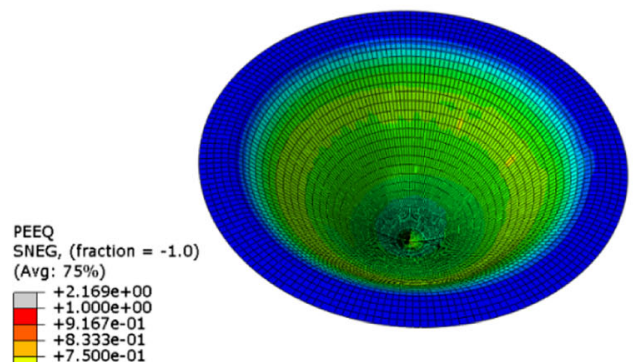

(a)

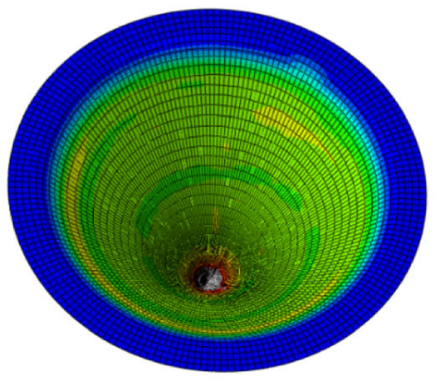

(c)

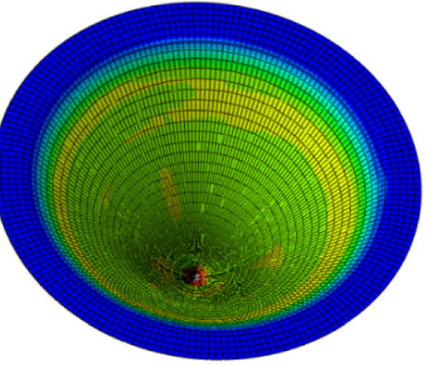

(b)

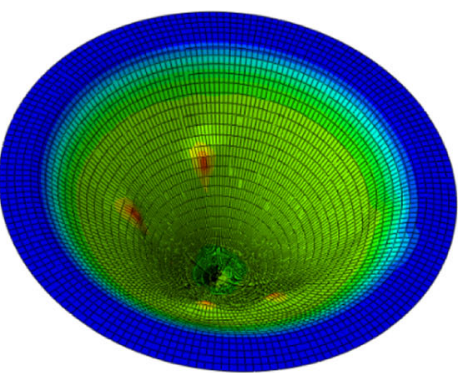

(d)

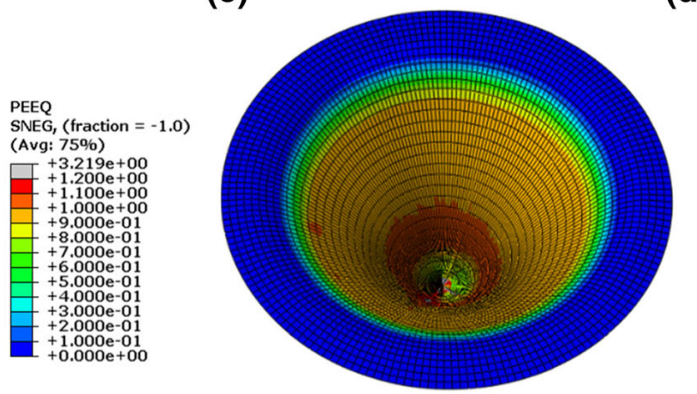

(e)

maximum pressure of $11.5 \mathrm{MPa}$, obvious wrinkling on the sidewall of the formed cone can be observed in Fig. 9d and thus resulted in deviation in both profile and height from the designed shape, shown in Fig. 10. For case 5 of the ISF process using a rigid tool,

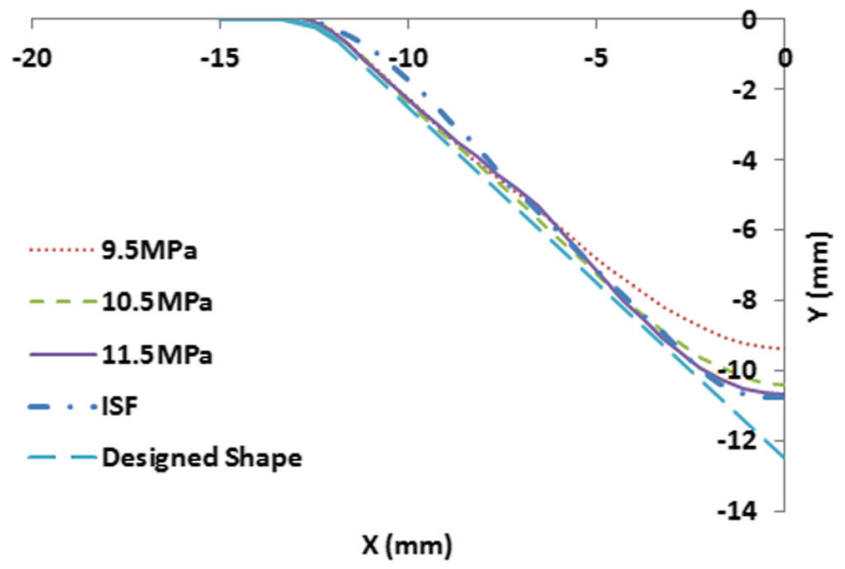

Fig. 10 Height $(Y)$ of formed cone shape along its radius $(X)$ although the cone height could reach the same value as that in case 4, an obvious profile deviation can be observed at the edge of the formed cone created at the initial stage of the ISF process, as shown in Fig. 10.

Figure 11 shows the thickness distributions of the formed shape by ISF-WJ case 2 and ISF case 5, respectively. Compared with the ISF-WJ case, the thickness distribution of the ISF case is more uniform; however, with much higher reduction of sheet thickness in ISF case, it indicates an overstretched deformation of the sheet resulted in over thinning of the sidewall of the conic shapes formed.

To obtain further understanding of both ISF-WJ and ISF processes, the equivalent stress distributions of the formed cone shape during the forming process are inspected for cases 4 and 5. As can be seen in Fig. 12, for ISF-WJ case 4 , the maximum stress occurs at the bottom region of the cone during the forming process. At the sidewall of the formed cone, the stress levels are much lower. During the majority period of the forming process, no obvious wrinkling can be observed until the deformation reaches $75 \%$ of the total deformation to form the conic shape, as shown in 
Fig. 11 Distributions of sheet thickness by ISF-WJ and ISF. a Case 2. b Case 5

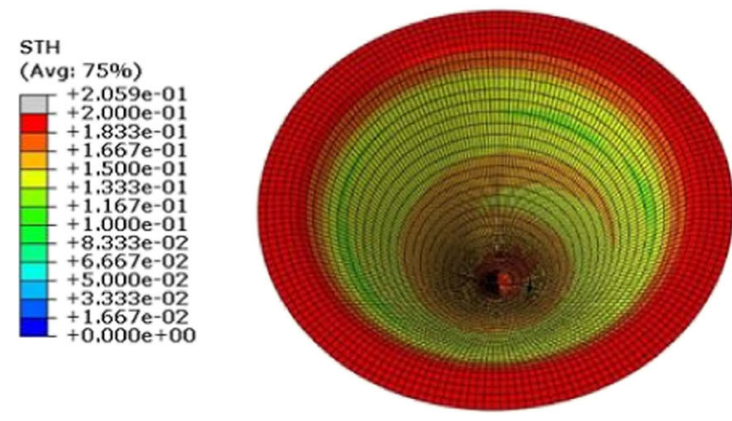

(a)

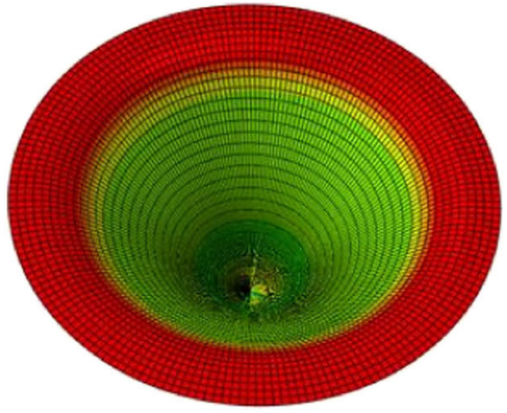

(b)
Fig. 12a-c. However, when approaching the end of ISF-WJ forming process, as shown in Fig. 12d, non-uniformly distributed and higher stresses can be observed at the sidewall of the formed cone, as a result of the appearance of wrinkles around the bottom area. This result suggests that wrinkling may occur at the final stage of forming of thin sheets. Comparing the stress results of ISF in Fig. 13 with those of ISF-WJ in Fig. 12, although the stress distribution patterns are not very different from that of the ISF-WJ, higher stress levels of the formed sheet can be observed in all corresponding deformation stages of the ISF process. This may be caused by a greater plastic deformation of the sheet induced by the rigid tool contact.

\subsection{Experimental test results}

In the experimental testing, both ISF-WJ and ISF processes are conducted by using the developed system. Figure 14 shows the produced samples of $45^{\circ}$ conic shape made by both ISF-WJ and the ISF. As can be seen, all the testing cases can be successfully performed by using the developed system. For case 2 by ISF-WJ (Fig. 14a), slight wrinkling can be observed at the tip area of the cone, while for case 5 by ISF (Fig. 14c), no wrinkling occurs. However, for case 3 using a thinner sheet by ISF-WJ, obvious wrinkling can be observed at the tip area, as shown in Fig. 14b. Thus, it is important to select the maximum forming pressure by considering the sheet material and thickness to be formed. The experimental observations of wrinkling are in line with the results of the equivalent plastic strain distributions modeled by the FE simulation, where in case 2, large strains at small region of the conic tip can be observed, while in case 3 , the localized region has higher strains on a thinner sheet, causing wrinkling.

In the ISF-WJ process, the sheets are deformed without using rigid tools, therefore improving the surface finish of the formed parts. In this work, the surface finish
Fig. 12 Distributions of von Mises stress by ISF-WJ case 4: a $25 \%$, b $50 \%$, c $75 \%$, and $\mathbf{d} 100 \%$ of the total deformation

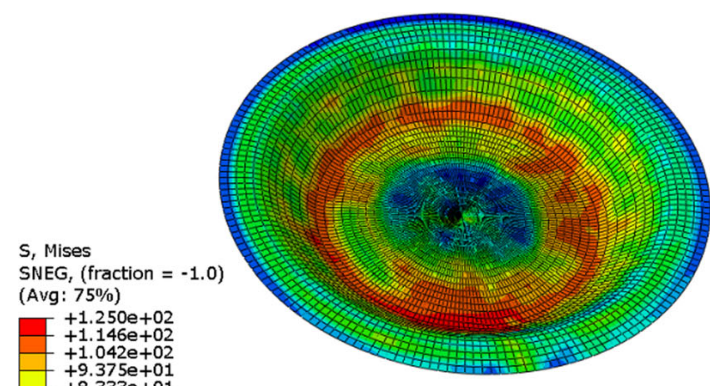

(a)

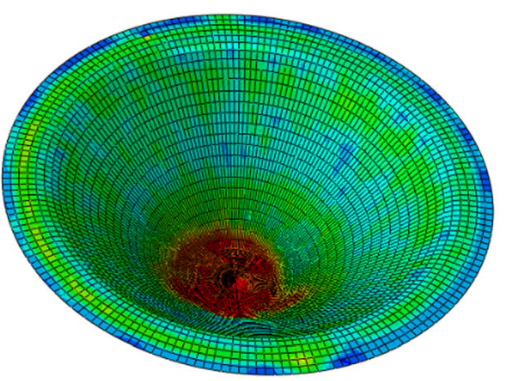

(c)

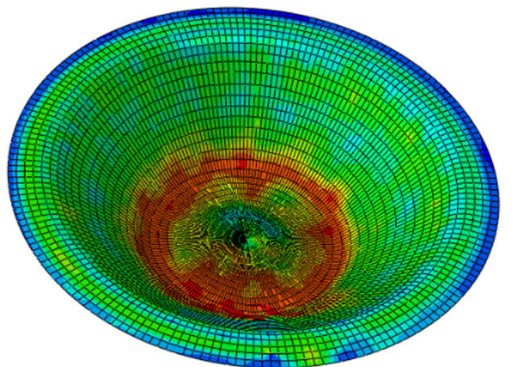

(b)

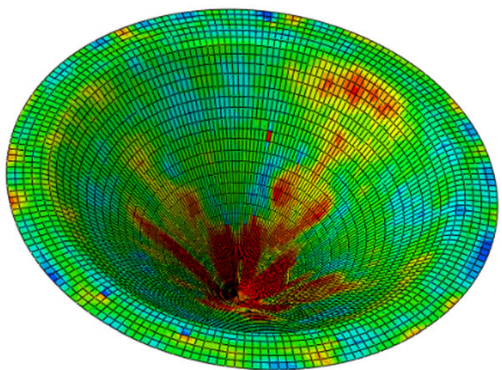

(d) 
Fig. 13 Distributions of von

Mises stress by ISF case 5: a 25\%,

b $50 \%, \mathbf{c} 75 \%$, and $\mathbf{d} 100 \%$ of the

total deformation

Fig. 14 Formed $45^{\circ}$ conic shapes by ISF-WJ and ISF. a Case 2. b Case 3. c Case 5

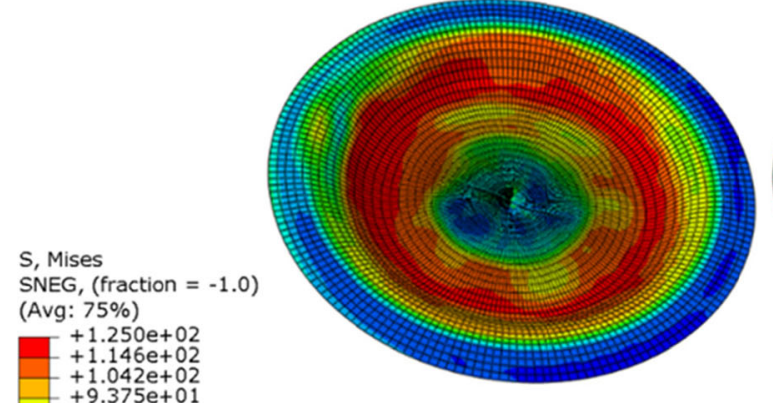

(a)

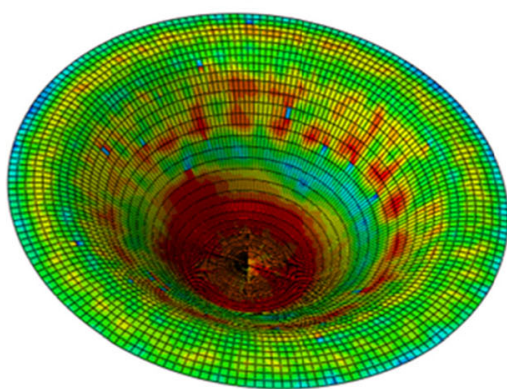

(c)

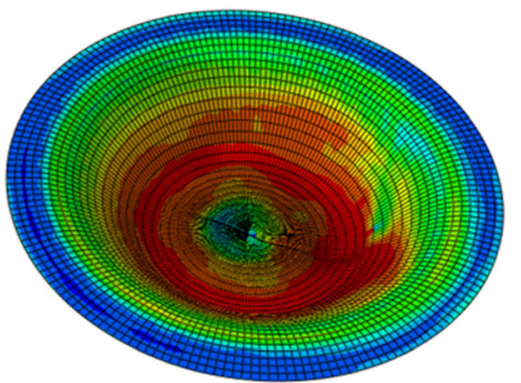

(b)

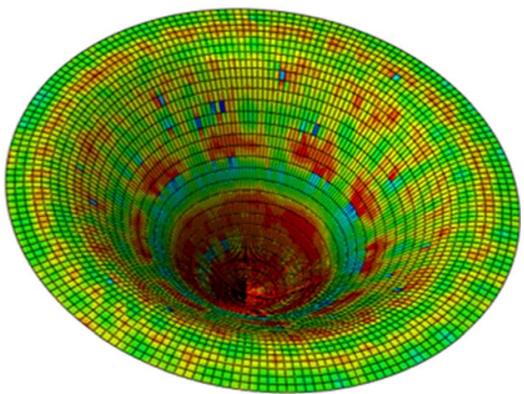

(d)

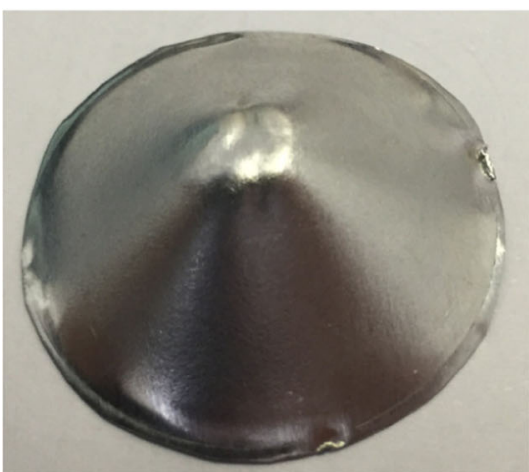

(a)

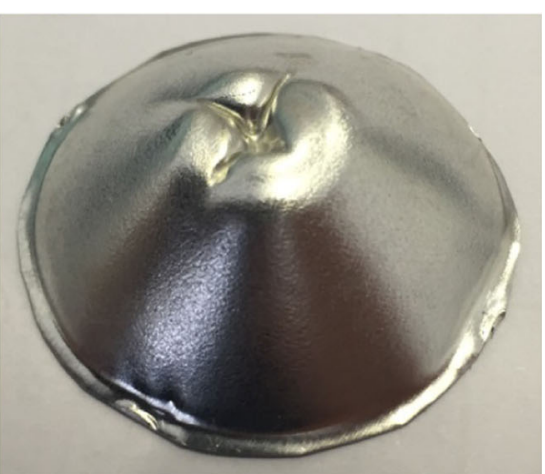

(b)

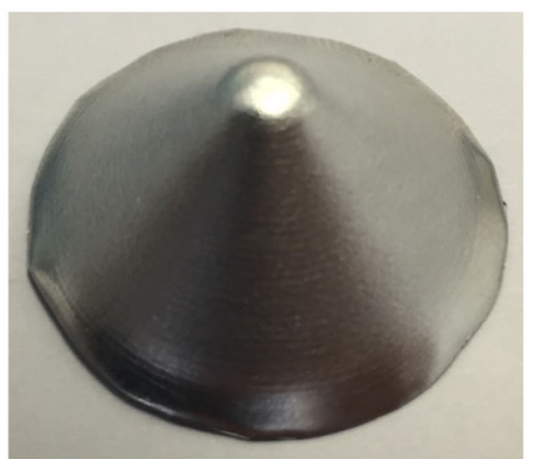

(c) 
Fig. 15 Surface finishing of conic shapes. a Case 2-ISF-WJ $0.17 \mathrm{~mm}$. b Case 3 - ISF-WJ $0.1 \mathrm{~mm}$. c Case 5-ISF $0.17 \mathrm{~mm}$

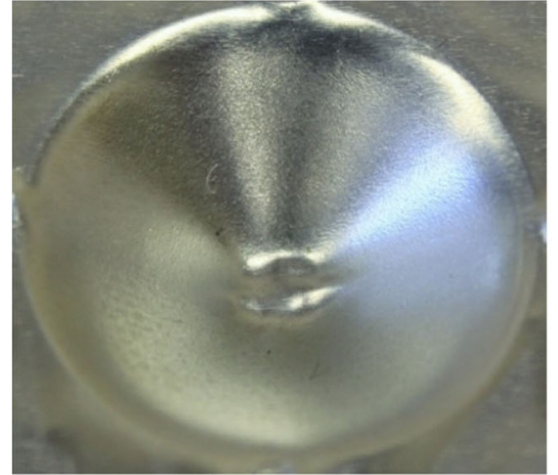

(a)

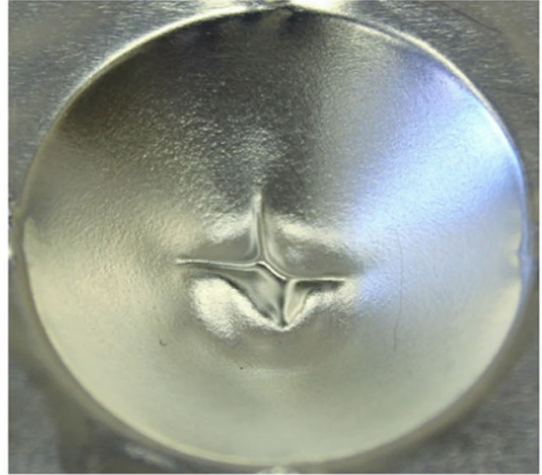

(b)

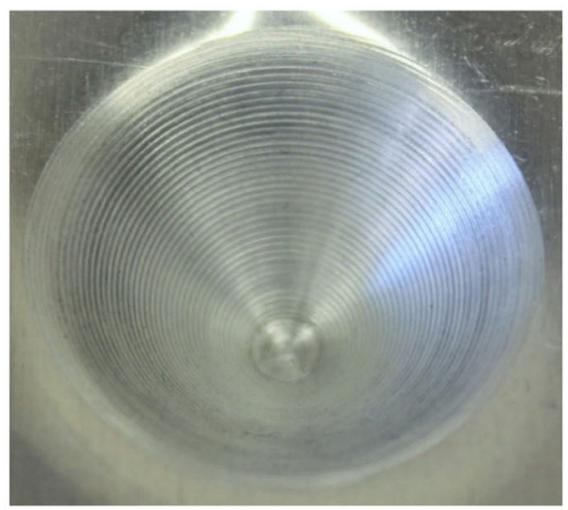

(c)

of the conic shapes formed in cases 2, 3, and 5 is examined, as shown in Fig. 15. It can be observed that the surface of the ISF-WJ conic shapes has a better surface finishing than that of the ISF cone. For the ISF cone, even with the use of lubricant, tool marks are clearly visible due to the tool scratching on the sheet surface. However, a separate ISF tool with a hemispherical tool head may be used to replace the water jet nozzle when the developed system is used for ISF processes to improve surface finishing.
To obtain the detailed variations of the surface finishing of the formed shapes, the surface roughness of cones produced in cases 2 and 5 is measured, as shown in Fig. 16. As can be seen, the surface roughness obtained by the ISF is higher compared to that produced by the ISF-WJ. Table 3 compares the surface roughness measurements of two processes using their Ra and Rz values. As can be seen in Table 3, the Ra value for the ISF sample is $4.77 \mu \mathrm{m}$ and that for the ISF-WJ sample is $3.03 \mu \mathrm{m}$, which equates to a reduction of surface roughness of about $37 \%$. If the developed nozzle is used as the tool for both ISF-
Fig. 16 Comparison of surface roughness profiles of conic shapes. a Case 2-ISF-WJ $0.17 \mathrm{~mm}$. b Case 5-ISF $0.17 \mathrm{~mm}$

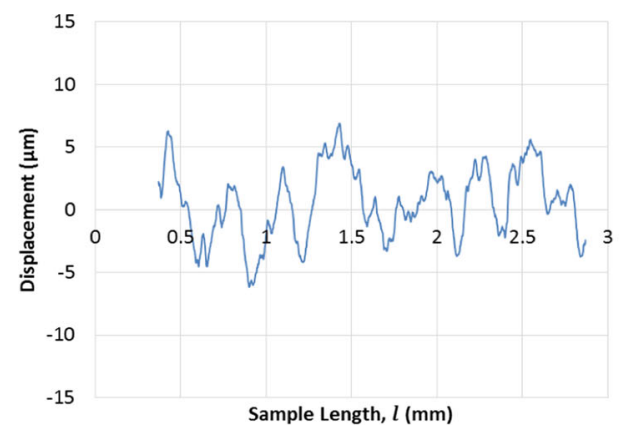

(a) Case 2 - ISF-WJ $0.17 \mathrm{~mm}$

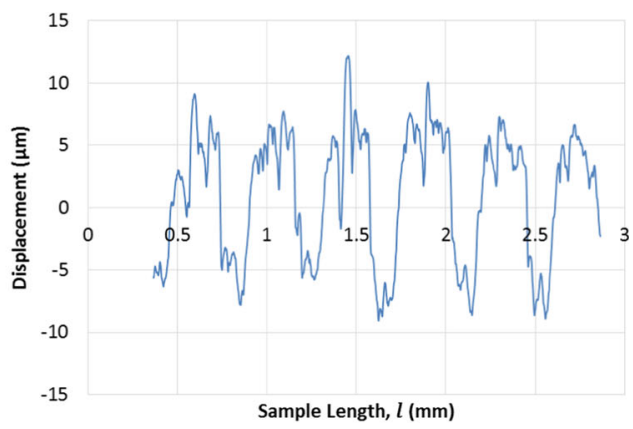

(b) Case 5 - ISF $0.17 \mathrm{~mm}$ 
Table 3 Comparison of surface roughness values

\begin{tabular}{lll}
\hline Case no. & $\mathrm{Ra}(\mu \mathrm{m})$ & $\mathrm{Rz}(\mu \mathrm{m})$ \\
\hline Case 2 & 3.03 & 10.20 \\
Case 5 & 4.77 & 17.42 \\
\hline
\end{tabular}

Open Access This article is distributed under the terms of the Creative Commons Attribution 4.0 International License (http:// creativecommons.org/licenses/by/4.0/), which permits unrestricted use, distribution, and reproduction in any medium, provided you give appropriate credit to the original author(s) and the source, provide a link to the Creative Commons license, and indicate if changes were made.
WJ and ISF processes, this result suggests that by employing the ISF-WJ process, sheet metal parts with better surface finishing can be obtained. However, future work can be performed to explore better water jet nozzle designs and toolpath strategies aiming to achieve better surface finishing for both ISF-WJ and ISF processes.

\section{Conclusions}

In this work, an ISF-WJ prototype machine and water jet nozzle design have been developed. Using this prototype machine, both ISF-WJ and ISF processes can be implemented. The material deformation behavior in the ISF-WJ process is investigated through both FE simulation and experimental testing approaches. The findings of this work can be summarized as follows:

1. The developed ISF-WJ prototype machine using two water jet pumps could successfully form thin-walled sheet metal parts.

2. Water jet nozzle designs with stepped features to reduce the nozzle diameter are a better design option to achieve higher forming pressure.

3. The ISF-WJ process has advantages in improving the surface finishing of the formed sheet parts without using any lubrication.

4. Different from the conventional ISF process, the water jet pressure plays an important role in the ISF-WJ process: if the forming pressure produced by water jet is too high, it may cause high levels of deformation in a localized area resulting in wrinkling of formed parts.

Acknowledgements The work was supported by the EU FP7 Marie Curie Actions International Incoming Fellowship Scheme FLEXFORM Project (628055) and International Research Staff Exchange Scheme MatProFuture Project (FP7-PEOPLE-2012-IRSES-318968). The authors are also grateful for the support of the National Natural Science Foundation of China Project no. 51675332.

\section{References}

1. Malhotra R et al (2010) Improvement of geometric accuracy in incremental forming by using a squeezing toolpath strategy with two forming tools. J Manuf Sci Eng 133(6):603-611

2. Jeswiet $\mathrm{J}$ et al (2005) Asymmetric single point incremental forming of sheet metal. Annals of CIRP 52(2):623-650

3. Emmens WC, Sebastiani G, van den Boogaard AH (2010) The technology of incremental sheet forming - a brief review of the history. J Mater Process Technol 210:981-997

4. Iseki H, Kato K, Sakamoto S (1989) Flexible and incremental sheet metal forming using a spherical roller. In: Proc. 40th JJCTP: p. 41-44

5. Matsubara S (1994) Incremental backward bulge forming of a sheet metal with a hemispherical head tool. Journal of the JSTP 35(406): 1311-1316

6. Araghi BT et al (2009) Investigation into a new hybrid forming process: incremental sheet forming combined with stretch forming. CIRP Ann Manuf Technol 58(1):225-228

7. $\mathrm{Lu} \mathrm{B}$ et al (2015) Investigation of material deformation mechanism in double side incremental sheet forming. Int J Mach Tools Manuf 93:37-48

8. Lu B et al (2014) Mechanism investigation of friction-related effects in single point incremental forming using a developed oblique roller-ball tool. Int J Mach Tools Manuf 85:14-29

9. Iseki H (1999) A simple deformation analysis for incremental bulging of sheet metal using high speed water jet. In: Proc. 6th ICTP: $p$. 1483-1490. Nuremberg, Germany

10. Iseki $H$ (2001) Flexible and incremental bulging of sheet metal using high-speed water jet. JSME Int J Series C 44(2):468-493

11. Iseki $H$, Nara $T$ (2007) Incremental bulging of sheet metal using water jet and shots. Key Eng Mater 344:575-582

12. Emmens WC (2006) Water jet forming of steel beverage cans. International Journal of Machine Tools \& Manufacture 46:1243-1247

13. Jurisevic B, Kuzman K, Junkar M (2006) Water jetting technology: an alternative in incremental sheet metal forming. Int $\mathrm{J}$ Adv Manuf Technol 31:18-23

14. Jurisevic B, Sajn V, Kosel F (2008) Introduction of laminated supporting tools in water jet incremental sheet metal forming. Int J Adv Manuf Technol 37:496-503

15. Sajn V, Jurisevic B, Kosel F (2011) Water jet incremental sheet metal forming: pressure distribution analysis. Int J Interact Des Manuf 5:95-102

16. Zhang Q, Zhang TT, Lei L, Dai MQ (2014) The high-pressure liquid jet incremental forming for the aluminum sheet. Proc IMechE Part B: J Engineering Manufacturing 229(4):682-690 